\title{
Heberlein Receives 2009 Plasma Chemistry Award
}

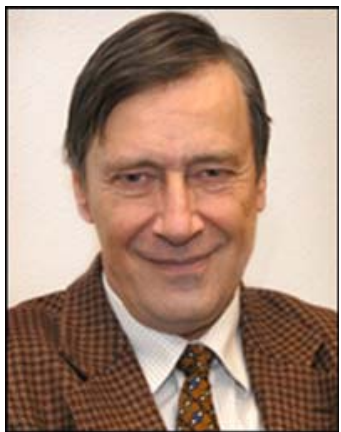

Joachim V.R. Heberlein

The Board of Directors of the International Plasma Chemistry Society (IPCS) has announced the winner of the 2009 Plasma Chemistry Award, the highest recognition awarded by the IPCS for lifetime achievements in the field of the Plasma Chemistry.

The winner of the 2009 Plasma Chemistry Award is Prof. Joachim V.R. Heberlein, FASM, University of Minnesota. He has been cited for his significant contributions to thermal plasmas science; in particular, the understanding of plasma arc-electrode effects, and his achievements in the area of thermal plasma processing.

Prof. Heberlein received his Diploma in Physics from the University of Stuttgart in 1966, and his Ph.D. from the University of Minnesota in 1975. From 1975 to 1989, he was first a senior engineer and then manager for applied plasma research at the Westinghouse Research and Development Center in Pittsburgh. He joined the Department of Mechanical Engineering at the University of Minnesota in 1989.

Prof. Heberlein is a member and past chair of the Journal of Thermal Spray Technology Committee. In addition to serving as chair of the Thermal Spray Society Awards Committee and the International Thermal Spray Conference Programming Committee, Prof. Heberlein has authored or co-authored more than 138 journal papers in the field of thermal plasma science, and graduated 23 Ph.D. students and 28 M.S. students. Prof. Heberlein is a Fellow of ASM and the International Union of Pure and Applied Chemistry (IUPAC) and served on the IUPAC Subcommittee for Plasma Chemistry from 1984 to 1994; he chaired the committee from 1992 to 1993 . He was also Chairman of the organizing committee of the 12th International Symposium on Plasma Chemistry in Minneapolis, Minnesota, in 1995. Prof. Heberlein was one of the founders of the International Plasma Chemistry Society and served the IPCS as treasurer until 2008.

A special award lecture is scheduled during the 19th International Symposium on Plasma Chemistry in Bochum, Germany, July 26-31, 2009.

JTST extends warmest congratulations to Prof. Heberlein! 